\title{
Clinical and economic burden of head and neck cancer: a nationwide retrospective cohort study from France
}

This article was published in the following Dove Press journal:

ClinicoEconomics and Outcomes Research

\author{
Antoine Schernberg (1D \\ Luis Sagaon-Teyssier (iD) 2,3 \\ Michaël Schwarzinger (iD ${ }^{3,4}$ \\ On behalf of the EPICORL \\ Study Group \\ 'Department of Radiation Oncology, \\ Hôpital Tenon, AP-HP, Paris, France; ${ }^{2}$ Aix \\ Marseille Univ, INSERM, IRD, SESSTIM, \\ Marseille, France; ${ }^{3}$ Translational Health \\ Economics Network (THEN), Paris, \\ France; ${ }^{4}$ Infection Antimicrobials \\ Modeling \& Evolution (IAME), UMR I I37, \\ Institut National de la Santé et de la \\ Recherche Médicale (INSERM), \\ Université Paris Diderot, Sorbonne Paris \\ Cité, Paris, France
}

Objectives: To evaluate the clinical and economic burden of head and neck squamous cell carcinoma (HNSCC) in France.

Methods: All 53,255 incident adult patients discharged with a first diagnosis of HNSCC in 2010-2012 were identified from the 2008-2013 French National Hospital Discharge (PMSI) database. We conducted a retrospective longitudinal analysis of prognosis and direct costs attributable to HNSCC.

Results: Direct medical costs attributable to HNSCC care amounted to 665 million euros in 2012 in France. The majority (62\%) of incident patients were 64 years old or less at HNSCC diagnosis and incurred 1.3-fold higher mean direct costs as compared to elderly patients $(41,909$ vs 32,221 euros over 3 years, respectively; $\mathrm{p}<0.001)$. HNSCC stage at initial treatment was the major driver of mean (SD) direct costs over 3 years $(p<0.001)$ : 19,819 $(23,150)$ euros in $31 \%$ patients diagnosed at early stage; $46,791(34,841)$ euros in $60 \%$ patients diagnosed at locally advanced stage; and 43,377 $(33,953)$ euros in 9\% patients diagnosed with distant metastasis. About half patients died over 3 years at a median (IQR) age of 63 (56-75) years resulting in 10.9 years-of-life lost on average per incident patient. Conclusion: The present study suggests that the clinical and economic burden of HNSCC is substantial in France.

Keywords: head and neck squamous cell carcinoma, prognosis, costs, burden of disease, National Hospital discharge database

\section{Introduction}

Head and neck squamous cell carcinoma (HNSCC) involve various primary cancer sites from nasopharynx to larynx that are overall frequent with an estimated prevalence of 1.4 million adults affected in high-income countries in 2015. ${ }^{1,2}$ HNSCC remain overall of poor prognosis, ${ }^{3}$ and recent marketing of new immunotherapy is expected to lower the burden of HNSCC. ${ }^{4,5}$ However, early cost-effectiveness analyses conducted in the US and UK suggest that routine use of immunotherapy in HNSCC is most likely unaffordable in high-income countries. ${ }^{6,7,8}$ While cost-effectiveness analyses raise global concerns about price and long-term effects of immunotherapy, their generalizability to various health-care settings may have been overlooked as large variations are expected in direct cost estimates of HNSCC care.

A recent review on the economic burden of HNSCC pointed out that most cost studies were conducted in US Medicare patients aged 65+ years old with limited generalizability to the most frequent groups of middle-aged or European patients. ${ }^{9}$
Correspondence: Michaël Schwarzinger (THEN), 39 quai de Valmy, 75010 Paris, France

Tel +3366210 6676

Email michael.schwarzinger@transhealthecon.net 
In particular, tobacco smoking and heavy drinking are the main risk factors for HNSCC and account for larger population attributable fractions in Europe $(84.3 \%, 95 \% \mathrm{CI}$ : 72.6-90.3) as compared to North America (50.5\%, 95\% CI: $34.2-62.2) .{ }^{10}$ As both risk factors also involve frequent comorbidities all along HNSCC care, including second primary cancers, ${ }^{11}$ direct costs of HNSCC care may be relatively higher in Europe. ${ }^{12}$ In addition, about $60 \%$ of patients are diagnosed at a locally advanced stage ${ }^{3}$ and receive combined-modality treatments to decrease the risk of relapse. ${ }^{13}$ To the best of our knowledge, only one study disentangled direct costs by phase-of-care in oropharynx cancer and found that relapse treatment was associated with dramatic increases in direct costs as compared to initial treatment. ${ }^{14}$ Such heterogeneity in both prognosis and costs depending on relapse occurrence does matter for cost-effectiveness models but cannot be assessed from cost studies limited to HNSCC stage at diagnosis. ${ }^{9}$

In this study, we identified all incident cases of HNSCC discharged from French hospitals in the years 2010 to 2012 and assessed the clinical and economic burden of HNSCC at three levels: prevalent direct costs attributable to HNSCC care in 2012 in France; clinical outcomes and direct costs over 3 years, overall and by HNSCC stage at initial treatment; and monthly direct costs by phase-of-care including relapse treatment.

\section{Materials and methods Data source}

The data source was the French National Hospital Discharge (PMSI) database in the years 2008-2013. The database contains all public and private hospital claims for acute and post-acute care. The standardized discharge summary includes: patient's demographics (gender, age, postal code of residency); primary and associated discharge diagnosis codes according to the WHO International Classification of Diseases, tenth revision (ICD-10); medical procedures performed; length of stay, entry and discharge modes (including in-hospital death). Using unique anonymous identifiers, we conducted a retrospective longitudinal analysis of prognosis and direct costs attributable to HNSCC care. $^{15,16}$

\section{Study population}

We included all adults residing in metropolitan France and discharged with a primary or associated discharge diagnosis code of HNSCC (ICD-10: C00-C06; C09-C14; C30.0; C31; C32) in the years 2008-2012 (see the full coding dictionary in Supplementary Table S1). To minimize a possible misclassification bias of a relapse case as an incident case, we excluded all patients first diagnosed with HNSCC in 2008-2009 or recorded with a personal history of cancer at first diagnosis of HNSCC in 2010 $2012 .{ }^{17}$ For all selected patients, hospital discharge data of the year 2013 were used to ascertain vital status and refine direct costs until fixed censoring at July 1, 2013 (see Supplementary Methods and Tables S1-S4).

\section{HNSCC characteristics}

Primary HNSCC sites were identified from the primary discharge diagnosis recorded at first HNSCC surgery or panendoscopy, and disentangled in eight categories: nasal cavity/paranasal sinuses; nasopharynx; lip; oral cavity; oropharynx; hypopharynx; larynx; and ill-defined HNSCC. ${ }^{18}$

All patients entered an initial treatment phase covering the first six months after HNSCC diagnosis. ${ }^{14,19}$ We considered three cancer stages independent of the primary HNSCC site: distant metastasis stage; locally advanced stage; and early stage. ${ }^{18} \mathrm{~A}$ distant metastasis stage was identified by any record of distant metastasis during initial treatment. A locally advanced stage was defined by any discharge diagnosis indicating locoregional extension or any initial treatment eliminating an early stage (eg, chemotherapy). An early stage was recorded by default for other patients.

After six months, patients identified at locally advanced or early stage became at risk of relapse. Relapse was identified by the first hospital record of a local relapse of the primary HNSCC site or any new event indicative of extension (distant metastasis, locoregional extension, or chemotherapy). Patients who relapsed were followed over a relapse treatment phase (starting at first hospital record of relapse); other patients were followed by default over a continuing care phase (starting at six months after HNSCC diagnosis).

The Charlson Comorbidity Index $(\mathrm{CCI})^{20}$ is the most widely used comorbidity index in HNSCC care $^{21}$ and we identified each comorbidity with use of ICD-10 coding algorithms validated in large hospital discharge databases ${ }^{22}$ including the French National Hospital Discharge database. ${ }^{23}$ Patients were categorized at each phase-of-care (initial treatment, relapse treatment, or continuing care) according to a $\mathrm{CCI}$ of $0 ; 1 ; 2$; or $\geq 3$. 


\section{Direct costs attributable to cancer care}

Of all 1,012,500 hospital stays recorded for the study population, $877,544(86.7 \%)$ were attributable to cancer care following the methodology developed by the French National Cancer Institute. ${ }^{24}$ Hospital expenses are reimbursed according to national Diagnosis-Related Group (DRG)-related tariffs that vary by year and public/private sector. Since national DRG-related tariffs showed minor $( \pm 1 \%)$ variations by year, we relied on the national DRGrelated tariffs of the year without adjustment on inflation. In addition, national DRG-related tariffs are lower in the private sector as compared to the public sector because medical procedures are directly reimbursed to physicians in the private sector. Therefore, we relied on national DRG-tariffs of the public sector to fully assess hospital expenses in the private sector. Hospital stays were categorized with use of the DRG classification system to disentangle several main cost categories: ${ }^{24}$ diagnostic workup; surgery (including reconstructive surgery); radiation therapy; chemotherapy (including actual expenses of targeted therapy cetuximab); supportive care (including adverse effects of treatments); and palliative care (from first record of palliative care onwards).

Radiation therapy is usually performed in an outpatient setting. In the public sector, radiation therapy is also reimbursed with use of national DRG-tariffs. In the private sector, radiation therapy is directly reimbursed to physicians and cannot be identified in the hospital discharge database. However, all modality treatments other than radiation therapy administered in the private sector were observed in the study population. Therefore, we used HNSCC management recommendations by primary HNSCC site ${ }^{13}$ to impute the administration of radiation therapy in the private sector: a) in patients diagnosed at early stage and treated with exclusive radiation therapy (ie, patients identified without surgery or radiation therapy in the public sector); and $b$ ) in patients diagnosed at locally advanced stage and treated with combined chemotherapy and radiation therapy (ie, patients identified with chemotherapy and without radiation therapy in the public sector) (Supplementary Table S2). We relied on the average costs of radiation therapy in the public sector for patients initially treated at early or locally advanced stage to value the administration of radiation therapy imputed in the private sector. No imputation was performed at other phases-of-care (ie, initial treatment with distant metastasis; relapse treatment) as radiation therapy is less frequently administered and usually performed in the public sector.

Medical transportation to/from hospital was estimated for each hospital stay with use of the minimum kilometric distance between the postal code of residency and hospital address. ${ }^{25}$ We considered two medical transportations per hospital stay (only one if the patient died at hospital) and the distribution of transportation mode (ambulance: $39 \%$; light health vehicle: $20 \%$; taxi: $37 \%$; other $4 \%$ ). ${ }^{26}$ Medical transportation was valued following French Social Security reimbursement rules based on transportation mode and kilometric distance. Regarding radiation therapy imputed in the private sector, medical transportation costs were estimated from the average costs of medical transportation in the public sector for patients receiving radiation therapy at early or locally advanced stage.

\section{Statistical analyses}

Prevalent direct costs of HNSCC care in France were estimated for the year 2012 that accrued the largest sample size with patients followed at all phases-of-care $(n=32,987)$. Direct costs were summed over the year 2012, overall and according to payer, hospital field, hospital sector, or main cost category.

Per-patient clinical outcomes and direct costs were estimated over 3 years in all patients diagnosed in the first semester of 2010 with complete follow-up $(n=9,714)$. Clinical outcomes assessed included: death rate over the follow-up; median (IQR) age at death; and average years-of-life lost per patient that combines death rate, age at death, and years-of-life lost with reference to the life table of the 2015 Global Burden of Disease Study. ${ }^{27}$ Mean (SD) direct costs were estimated over an exact follow-up of 3 years. Per-patient clinical outcomes and direct costs were compared by demographics and HNSCC characteristics.

Monthly direct costs were estimated by phase-of-care in the overall study population $(n=53,255) \cdot{ }^{14,19}$ Direct costs were summed over by patient and phase-of-care, overall and by main cost category. Since zero cost may be recorded for a main cost category, we used two-part models to estimate monthly costs by phase-of-care. Each two-part model combined the probability of non-zero costs (logistic regression) and the mean (SD) monthly estimate of non-zero costs (general linear model with gamma distribution) with adjustment on demographics and HNSCC characteristics. $^{28,29}$ 


\section{Results}

\section{Prevalent direct costs attributable to HNSCC care in 2012 in France}

Direct costs attributable to HNSCC care amounted to 665 million euros in 2012. About all (98\%) direct costs were covered by the French Social Security (Figure 1). Direct costs were primarily driven by acute care $(88 \%)$ and bore by the public sector $(69 \%)$.

Curative-intent treatments of HNSCC accounted for 356 (54\%) million euros in 2012 and were related to surgery (37\%), chemotherapy (36\%), and radiation therapy $(27 \%)$. Radiation therapy imputed in the private sector accounted for $45 \%$ of all radiation therapy costs. Actual expenses of targeted therapy cetuximab accounted for $28 \%$ of all chemotherapy costs, $10 \%$ of curative-intent treatment costs, and $5 \%$ of prevalent direct costs.

Medical transportation to/from hospital amounted to 76 (11\%) million euros and was primarily driven by radiation therapy (73\%) and then chemotherapy (18\%).

\section{Per-patient clinical outcomes and direct costs over 3 years}

The characteristics of 9,714 patients diagnosed with HNSCC in the first semester of 2010 and complete follow-up over 3 years are presented in Table 1. Overall, 4,456 (45.9\%) patients died over 3 years at a median (IQR) age of 63 (56-75) years resulting in 10.9 years-of-life lost on average per incident patient. HNSCC care was associated with mean direct costs of 38,212 euros over 3 years.

The majority $(62 \%)$ of incident patients was 64 years old or less at HNSCC diagnosis. HNSCC care was 1.3fold more costly in middle-aged patients as compared to elderly patients (41,909 vs 32,221 euros over 3 years, respectively; $\mathrm{p}<0.001)$. A late stage at initial treatment (locally advanced or distant metastasis) or an increased number of comorbidities was associated with poorer prognosis and increased mean direct costs over 3 years.

\section{Clinical outcomes and monthly costs of HNSCC by phase-of-care}

The characteristics of all 53,255 incident patients diagnosed with HNSCC in the years 2010 to 2012 are presented by phase-of-care in Table 2. As compared to patients initially treated at early stage $(29.6 \%)$, patients at locally advanced stage $(61.4 \%)$ had a higher death rate in the first six months $(10.4 \%$ vs $16.2 \%, \mathrm{p}<0.001)$ and then a higher relapse rate in the follow-up (13.4\% vs $32.5 \%$ at 18 months, $\mathrm{p}<0.001)$. Respectively, direct costs per month were 2.4-fold higher at initial treatment (2,566 vs 6,263 euros on average per month) and then 12.2-fold higher from relapse onwards (435 vs 5,320 euros on average per month).

Main cost categories showed marked differences by phase-of-care (Figure 2). Curative-intent treatment and related medical transportation accounted for the majority of direct costs at the initial treatment phase in patients at early stage $(1,419$ euros per month; $55.7 \%)$ or locally advanced stage (4,190 euros per month; 66.5\%). Curative-intent treatment and related medical transportation accounted for a minority of direct costs in patients with distant metastasis at initial treatment $(2,947$ euros per month; $40.3 \%)$ or relapsing in the follow-up (2,333 euros per month; $44.3 \%$ ) as the majority of direct costs was explained by supportive care (about 23\%) and palliative care (about 31\%). Actual expenses of targeted therapy cetuximab reached a maximum after relapse (973 euros per month; $18.5 \%$ ).

\section{Discussion}

In this nationwide study of all incident cases of HNSCC diagnosed in French hospitals in the years 2010 to 2012, we found that HNSCC incurred a substantial clinical and economic burden in France. Direct costs attributable to HNSCC care amounted overall to 665 million euros in 2012. Most (70\%) patients were initially treated at a late stage with poor prognosis and increased direct costs.

HNSCC incurs a substantial clinical burden of disease in France with an average of 10.9 years-of-life lost per incident patient. Several studies corroborate that the clinical burden of HNSCC may reach a peak in France. In the 2015 Global Burden of Disease study, French patients with HNSCC were estimated with the highest exposure levels to both tobacco smoking and heavy drinking among highincome countries. ${ }^{2,30}$ French men were also recorded with the highest incidence rates of $\mathrm{HNSCC}^{31}$ as well as the highest HNSCC-specific mortality rates. ${ }^{32,33}$

Only one study reported prevalent direct cost estimates for HNSCC care in France with use of the same data source for the year 2007. ${ }^{34}$ In comparison, the economic burden of HNSCC had seemingly doubled in five years from 323 million euros in 2007 to 665 million euros in 2012. Differences between the two studies are most likely related to study design and scope of direct costs. The previous cost study used a cross-sectional design limited 

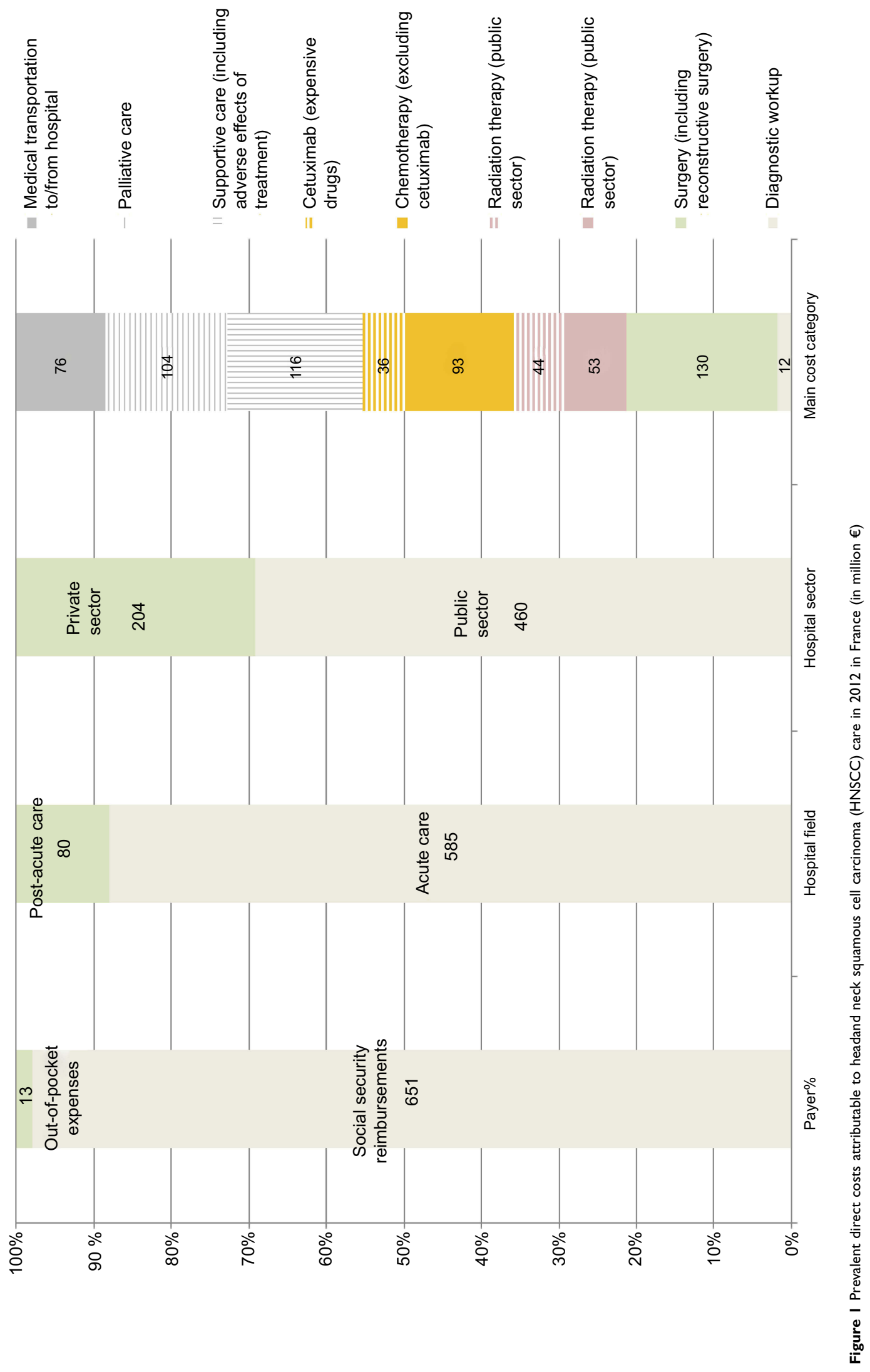
Table I Per-patient clinical outcomes and direct costs over 3 years

\begin{tabular}{|c|c|c|c|c|c|}
\hline $\begin{array}{l}\text { Characteristics of incident patients } \\
\text { diagnosed with HNSCC in the first } \\
\text { semester of } 2010\end{array}$ & $\mathbf{N}(\%)$ & $\begin{array}{l}\text { Death rate } \\
\text { over } 3 \\
\text { years, } n(\%)\end{array}$ & $\begin{array}{l}\text { Age at } \\
\text { death, } \\
\text { median } \\
\text { (IQR) }\end{array}$ & $\begin{array}{l}\text { Years-of- } \\
\text { life lost, } \\
\text { mean (SD) }\end{array}$ & $\begin{array}{l}\text { Direct costs } \\
\text { over } 3 \text { years, } \\
\text { mean (SD) }\end{array}$ \\
\hline All patients & $9,714(100)$ & $4,456(45.9)$ & $63(56-75)$ & $10.9(13.8)$ & $38,212(33,924)$ \\
\hline \multicolumn{6}{|l|}{ Gender } \\
\hline Men & $7,614(78.4)$ & $3,592(47.2)$ & $63(56-73)$ & $11.4(13.9)$ & $39,537(34,059)$ \\
\hline Women & $2,100(21.6)$ & $864(4 I . I)$ & $68(56-8 I)$ & $8.9(13.3)$ & $33,412(32,997)$ \\
\hline \multicolumn{6}{|l|}{ Age at HNSCC diagnosis } \\
\hline$<65$ years old & $6,008(61.9)$ & $2,470(4 I .1)$ & $57(52-6 I)$ & $13.0(16.0)$ & $41,909(35,513)$ \\
\hline $65+$ years old & $3,706(38.1)$ & $1,986(53.6)$ & $76(70-83)$ & $7.4(7.9)$ & $32,221 \quad(30,236)$ \\
\hline \multicolumn{6}{|l|}{ HNSCC site at diagnosis } \\
\hline Nasal cavity / paranasal sinuses & $497(5.1)$ & $223(44.9)$ & $75(64-83)$ & $8.0(11.7)$ & $30,71 ।(28,977)$ \\
\hline Nasopharynx & $326(3.4)$ & $137(42.0)$ & $62(53-73)$ & $10.9(14.7)$ & $38,669(26,532)$ \\
\hline Lip & $380(3.9)$ & $85(22.4)$ & $83(76-88)$ & $2.7(6.7)$ & $10,129(16,495)$ \\
\hline Oral cavity & $2,035(20.9)$ & $886(43.5)$ & $64(56-77)$ & $10.1(13.7)$ & $36,883(34,77 I)$ \\
\hline Oropharynx & $2,819(29.0)$ & $1,416(50.2)$ & $61(55-70)$ & $13.0(14.6)$ & $4 I, 589(33,64 I)$ \\
\hline Hypopharynx & $1,627(16.8)$ & $888(54.6)$ & $62(55-72)$ & $13.6(14.4)$ & $46,714(35,402)$ \\
\hline Larynx & I,799 (I8.5) & $676(37.6)$ & $67(58-78)$ & $8.0(12.1)$ & $35,309(33,524)$ \\
\hline III-defined HNSCC & $231(2.4)$ & $145(62.8)$ & $64(57-77)$ & $14.4(14.4)$ & $33,143(30,967)$ \\
\hline \multicolumn{6}{|l|}{ Cancer stage at initial treatment } \\
\hline Early & $2,978(30.6)$ & $822(27.6)$ & $75(6 I-84)$ & $4.9(9.8)$ & $19,819(23,150)$ \\
\hline Locally advanced & $5,856(60.3)$ & $2,861(48.9)$ & $62(55-73)$ & $12.2(14.3)$ & $46,79 I(34,84 I)$ \\
\hline Distant metastasis & $880(9.1)$ & $773(87.8)$ & $62(55-7 I)$ & $22.4(12.4)$ & $43,377(33,953)$ \\
\hline \multicolumn{6}{|l|}{ Charlson Comorbidity Index at initial treatment } \\
\hline 0 & $4,24 I(43.6)$ & $\mathrm{I}, 473(34.7)$ & $61(54-73)$ & $8.8(13.7)$ & $32,706(32,063)$ \\
\hline I & I,793 (I8.5) & $784(43.7)$ & $63(57-75)$ & $10.2(13.5)$ & $39,221(34,419)$ \\
\hline 2 & $\mathrm{I}, 722(17.7)$ & $939(54.5)$ & $63(56-75)$ & $12.9(14.1)$ & $42,875(34,244)$ \\
\hline$\geq 3$ & $1,958(20.2)$ & $1,260(64.4)$ & $66(58-77)$ & $14.2(13.3)$ & $45,118(35,145)$ \\
\hline
\end{tabular}

Notes: Comparison of survival (log-rank test) and years-of-life lost or costs per patient (Kruskal-Wallis test) were statistically significant for all characteristics. Abbreviations: HNSCC, head and neck squamous cell carcinoma.

to hospital stays with a discharge diagnosis of HNSCC. In contrast, we conducted a retrospective longitudinal analysis to encompass all hospital stays attributable to cancer care after HNSCC diagnosis, irrespective of HNSCC recording in the follow-up. ${ }^{24}$ In addition, we took into account all direct costs related to hospital care including post-acute care (12\%), out-of-pocket expenses for inpatient stays (2\%), and medical transportation to/from hospital (11\%). Differences between the two studies are unlikely related to valuation methods. National DRG-related tariffs for HNSCC care remained stable from 2008 to 2013. Also, radiation therapy costs in the private sector were imputed in both studies. In the previous cost study, radiation therapy costs in the public sector were roughly inflated according to the case-mix of public/private radiation therapy for all cancer care. In contrast, we individualized imputation by primary HNSCC site and stage. However, imputation of radiation therapy in the private sector accounted for $<7 \%$ of prevalent direct costs.

Inference from cost studies conducted in US Medicare patients aged $65+$ years old may not be warranted to other populations of HNSCC patients. ${ }^{9}$ The majority $(62 \%)$ of incident HNSCC patients were 64 years old or less in France, and we found that direct costs over 3 years were 1.3-fold higher in middle-aged patients as compared to elderly patients. In particular, HNSCC diagnosis in 
Table 2 Clinical outcomes and direct costs of HNSCC, by phase-of-care

\begin{tabular}{|c|c|c|c|c|c|}
\hline \multirow[t]{2}{*}{$\begin{array}{l}\text { Characteristics of incident patients } \\
\text { diagnosed with HNSCC in } 2010- \\
2012(\mathrm{~N}=53,255)\end{array}$} & \multicolumn{3}{|c|}{ Initial treatment } & \multicolumn{2}{|c|}{$\begin{array}{l}\text { Follow-up care in patients } \\
\text { initially treated at early or } \\
\text { locally advanced stage }\end{array}$} \\
\hline & Early stage & $\begin{array}{l}\text { Locally } \\
\text { advanced } \\
\text { stage }\end{array}$ & $\begin{array}{l}\text { Distant } \\
\text { metastasis }\end{array}$ & $\begin{array}{l}\text { Relapse } \\
\text { treatment }\end{array}$ & $\begin{array}{l}\text { Continuing } \\
\text { care (without } \\
\text { relapse) }\end{array}$ \\
\hline All patients by phase-of-care, $n$ (\%) & I5,747 (29.6) & $32,723(61.4)$ & $4,785(9.0)$ & $13,375(25.1)$ & $26,496(49.8)$ \\
\hline \multicolumn{6}{|l|}{ Gender, n (\%) } \\
\hline Men & $|\mathrm{I}, 4| 4(72.5)$ & $26,296(80.4)$ & $3,938(82.3)$ & I0,883 (8I.4) & $20,114(75.9)$ \\
\hline Women & $4,333(27.5)$ & $6,427(19.6)$ & $847(17.7)$ & $2,492(18.6)$ & $6,382(24.1)$ \\
\hline \multicolumn{6}{|l|}{ Age at HNSCC diagnosis, n (\%) } \\
\hline$<65$ years old & $7,762(49.3)$ & $21,767(66.5)$ & $2,978(62.2)$ & $9,291(69.5)$ & $16,253(6 \mid .3)$ \\
\hline $65+$ years old & $7,985(50.7)$ & $10,956(33.5)$ & $\mathrm{I}, 807(37.8)$ & $4,084(30.5)$ & $10,243(38.7)$ \\
\hline \multicolumn{6}{|l|}{ HNSCC site at diagnosis, n (\%) } \\
\hline Nasal cavity / paranasal sinuses & $\mathrm{I}, 266(8.0)$ & $\mathrm{I}, 303(4.0)$ & $285(6.0)$ & $612(4.6)$ & $\mathrm{I}, 567(5.9)$ \\
\hline Nasopharynx & $389(2.5)$ & I, $187(3.6)$ & $205(4.3)$ & $418(3.1)$ & $859(3.2)$ \\
\hline Lip & $\mathrm{I}, 857(\mathrm{II} .8)$ & $257(0.8)$ & $43(0.9)$ & $15 \mid(I . I)$ & $\mathrm{I}, 788(6.8)$ \\
\hline Oral cavity & $3,906(19.9)$ & $6,372(19.5)$ & $805(16.8)$ & $2,895(21.6)$ & $5,612(21.2)$ \\
\hline Oropharynx & $2,787(10.5)$ & II,079 (33.9) & $1,514(31.6)$ & 4,35 I (32.6) & $6,862(25.9)$ \\
\hline Hypopharynx & $\mathrm{I}, 4 \mathrm{II}(9.1)$ & $6,562(20.0)$ & $\mathrm{I}, 075(22.5)$ & $2,723(20.4)$ & $3,709(14.0)$ \\
\hline Larynx & $4,|3|(26.2)$ & $4,793(14.6)$ & $668(13.9)$ & $1,953(14.6)$ & $5,557(21.0)$ \\
\hline III-defined HNSCC & - & $\mathrm{I}, \mathrm{I} 70(3.6)$ & $190(4.0)$ & $272(2.0)$ & $542(2.0)$ \\
\hline \multicolumn{6}{|l|}{ Charlson Comorbidity Index, n (\%) } \\
\hline 0 & $8,231(52.3)$ & I3,954 (42.6) & $\mathrm{I}, 143(23.9)$ & $4,736(35.4)$ & $|3,6| 4(5 \mid .4)$ \\
\hline I & $2,917(18.5)$ & $5,966(18.2)$ & $560(11.7)$ & $2,643(19.7)$ & $5,200(19.6)$ \\
\hline 2 & I,97I (I2.5) & $5,818(17.8)$ & $1,210(25.3)$ & $2,483(18.6)$ & $3,180(12.0)$ \\
\hline$\geq 3$ & $2,628(16.7)$ & $6,985(21.4)$ & I,872 (39.I) & $3,513(26.3)$ & $4,502(17.0)$ \\
\hline \multicolumn{6}{|l|}{ Clinical outcomes } \\
\hline Follow-up, mean (SD) months & $5.6(1.4)$ & $5.5(1.4)$ & $9.4(9.2)$ & $9.6(8.7)$ & $16.6(10.8)$ \\
\hline Death rate over the follow-up, $\mathrm{n}(\%)$ & $\mathrm{I}, 64 \mathrm{I}(10.4)$ & $5,298(16.2)$ & $3,855(80.6)$ & $6,55 I(49.0)$ & $3,211(12.1)$ \\
\hline $\begin{array}{l}\text { Relapse rate at } 18 \text { months, cumulative inci- } \\
\text { dence }(95 \% \mathrm{Cl})\end{array}$ & $13.4(12.9-13.9)$ & $32.5(32.0-33.0)$ & - & - & - \\
\hline Direct costs per month, mean (SD) euros & $2,566(3,156)$ & $6,263(3,334)$ & $7,340(2,635)$ & $5,320(3,365)$ & $435(1,236)$ \\
\hline
\end{tabular}

Notes: Cumulative incidence functions of relapse during continuing care were estimated for patients initially treated at early or advanced stage, while taking into account the competing risk of death. Patients with distant metastasis at initial treatment had a high death rate and direct costs per month were computed to the end of follow-up rather than the first six months

Abbreviations: HNSCC, head and neck squamous cell carcinoma.

middle-aged patients was significantly associated with male gender, primary HNSCC sites of poor prognosis, a late stage at initial treatment, and a higher rate of comorbidities that were all significantly associated with increased direct costs over 3 years.

This study provides new insights for cost-effectiveness analyses carried in the HNSCC care setting. The majority
$(60 \%)$ of patients was initially treated at a locally advanced stage with the highest direct costs $(46,791$ euros over 3 years). As evidenced by the phase-of-care approach, the economic burden in these patients was majored by the intensity of combined-modality treatments at the initial treatment phase ( $66.5 \%$ of 6,263 euros per month) as well as supportive and palliative care following frequent relapses 


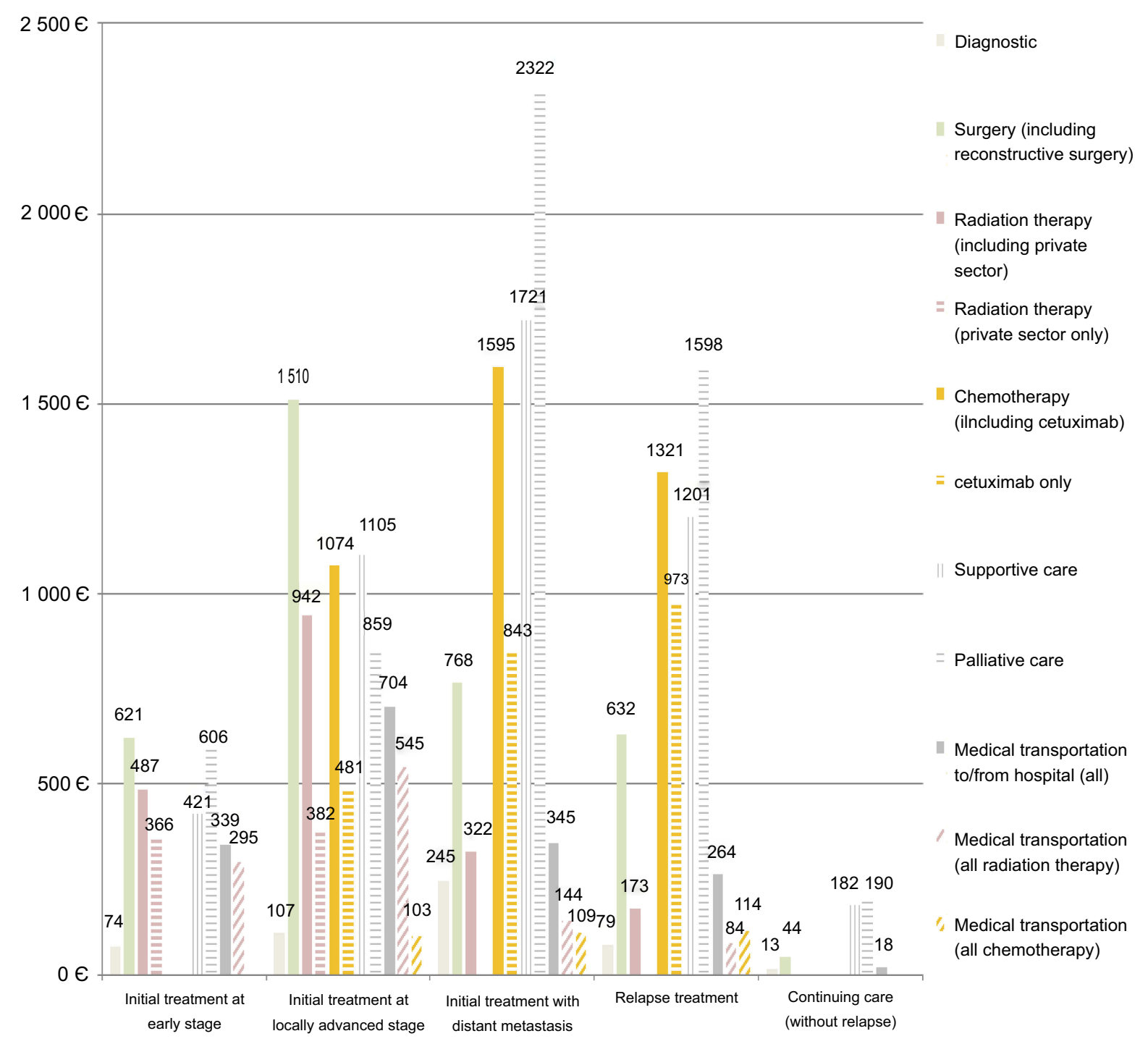

Figure 2 Mean monthly costs of headand neck squamous cell carcinoma (HNSCC), by phase-of-care and main cost category.

Notes: Direct costs include reimbursements to public/private hospitals in acute and post-acute care, out-of-pocket expenses for inpatient stays, radiation therapy imputed in the private sector, and medical transportation to/from hospital.

(54\% of 5,320 euros per month). Such heterogeneity in both outcomes and costs over time supports the identification of a relapse state in cost-effectiveness analyses. In addition, we found that expensive-targeted therapy cetuximab accounted for a relatively low proportion (5\%) of prevalent direct costs, eg, about half costs of medical transportation to/ from hospital. It questions whether any cost-effectiveness threshold may be meaningful to assess the value of new salvage therapy. ${ }^{35,36}$

The strengths of our study outline its limitations. Indeed, this study is based on a nationwide sample of all incident cases of HNSCC discharged from French hospitals, but all measurements relied on administrative records. Classification of malignant tumors based on TNM staging [extent of the tumor $(\mathrm{T})$, extent of spread to the lymph nodes $(\mathrm{N})$, and presence of metastasis $(\mathrm{M})]$ is not recorded in the standardized discharge summary. Therefore, we constructed a composite variable to identify a HNSCC stage at initial treatment and relapse in the follow-up and found consistent results with cancer registries. ${ }^{3}$ Regarding valuation methods, we made several assumptions in the private sector by using public National DRG-related tariffs and imputing radiation therapy. Presumably, the impact was limited on the study results as the DRG system is the same in both sectors and most (69\%) direct costs were eventually bored by the public sector. Direct costs assessed in this study covered all costs related to hospital care, while outpatient costs related to physician visits and lab/imaging exams should also be considered. However, outpatient 
costs are minimal relative to hospital costs, in particular in France.

\section{Conclusion}

HNSCC care was associated with a substantial clinical and economic burden in France in 2010-2012. Less than one-third of HNSCC patients were treated at early stage. Increasing prevention and early detection strategies are likely cost-effective to decrease the burden of HNSCC. The study results also suggest that the economic evaluation of salvage therapy with new immunotherapy should be country-specific and put in the global context of HNSCC prognosis and direct costs.

\section{Ethics approval and informed consent}

The EPICORL study was approved by the French National Commission for Data Protection (CNIL DE-2015-025) who granted access to the French National Hospital Discharge database for the years 2008 to 2013. The requirement for informed consent was waived because the study used de-identified data.

\section{Data availability}

Access to the French National Hospital Discharge (PMSI) database is restricted by French law.

\section{Acknowledgments}

The EPICORL (EPIdémiologie des Cancers ORL) Study Group includes: Sylvain Baillot, MSc, Translational Health Economics Network (THEN), Paris, France; Mélina Bec, MSc, Health Economics \& Outcomes Research department, MSD France; Lynda Benmahammed, MD, Medical Advisor Oncology, MSD France; Caroline Even, MD, PhD, Department of Head \& Neck Surgical \& Medical Oncology, Institut de cancérologie Gustave Roussy, Villejuif, France; Lionel Geoffrois, MD, PhD, Department of Medical Oncology, Institut de cancérologie de Lorraine Alexis Vautrin, Vandoeuvre Les Nancy, France; Florence Huguet, MD, PhD, Department of Radiation Oncology, Hôpital Tenon, AP-HP, France; Béatrice Le Vu, MD, MSc, Stratégie et Gestion Hospitalière, UNICANCER Fédération Nationale des Centres de Lutte Contre le Cancer, Paris, France \& Translational Health Economics Network (THEN), Paris, France; Laurie Lévy-Bachelot, $\mathrm{PhD}$, Health Economics \& Outcomes Research department, MSD France; Stéphane Luchini, PhD, CNRS, GREQAMIDEP, Marseille, France \& Translational Health Economics Network (THEN), Paris, France; Yoann Pointreau, MD, $\mathrm{PhD}$, Department of Radiation Oncology, ILC - Institut
inter-régionaL de Cancérologie, Centre Jean BernardClinique Victor Hugo, Le Mans, France; Camille Robert, PharmD, Health Economics \& Outcomes Research department, MSD France; Luis Sagaon Teyssier, PhD, AMU/ Inserm/IRD, UMR 912, Marseille, France \& Translational Health Economics Network (THEN), Paris, France; Antoine Schernberg, MD, MPH, Department of Radiation Oncology, Hôpital Tenon, AP-HP, France (at time of manuscript submission) and Department of Radiotherapy, Brachytherapy Unit, Gustave Roussy Cancer Campus, Villejuif, France; Michaël Schwarzinger, MD, $\mathrm{PhD}$, Translational Health Economics Network (THEN), Paris, France; Stéphane Temam, MD, PhD, Department of Head \& Neck Surgical \& Medical Oncology, Institut de cancérologie Gustave Roussy, Villejuif, France.

This study was supported by a research grant from MSD France. The funding source had no role in the study design, data collection, analysis, and interpretation of data, in the writing of the report and decision to submit the manuscript.

\section{Disclosure}

All authors have completed the ICMJE Competing Interest form and declare that: LST was an employee of Translational Health Economics Network (THEN), Paris, France; MS is the founder/CEO of Translational Health Economics Network (THEN), Paris, France that received research grants from MSD France as well as Abbvie, Gilead and Novartis, outside and unrelated to the submitted work. The authors report no other conflicts of interest in this work.

\section{References}

1. GBD. 2015 Disease and injury incidence and prevalence collaborators. Global, regional, and national incidence, prevalence, and years lived with disability for 310 diseases and injuries, 1990-2015: a systematic analysis for the Global burden of disease study 2015. Lancet. 2016;388 (10053):1545-1602. doi:10.1016/S0140-6736(16)31678-6

2. Global Burden of Disease Study 2015. Global Burden of Disease Study 2015 (GBD 2015) Results. Seattle, United States: Institute for Health Metrics and Evaluation (IHME); 2016. Available from: http:// ghdx.healthdata.org/gbd-results-tool.

3. Gatta G, Botta L, Sanchez MJ, et al. Prognoses and improvement for head and neck cancers diagnosed in Europe in early 2000s: the EUROCARE-5 population-based study. Eur J Cancer. 2015;51:21302143. doi:10.1016/j.ejca.2015.07.043

4. Seiwert TY, Burtness B, Mehra R, et al. Safety and clinical activity of pembrolizumab for treatment of recurrent or metastatic squamous cell carcinoma of the head and neck (KEYNOTE-012): an open-label, multicentre, phase 1b trial. Lancet Oncol. 2016;17(7):956-965. doi:10.1016/S1470-2045(16)30066-3

5. Ferris RL, Blumenschein G Jr., Fayette J, et al. Nivolumab for recurrent squamous-cell carcinoma of the head and neck. $N$ Engl J Med. 2016;375(19):1856-1867. doi:10.1056/NEJMoa1602252 
6. NICE. Nivolumab for treating squamous cell carcinoma of the head and neck after platinumbased chemotherapy; 2017. Available from: https:// www.nice.org.uk/guidance/TA490/chapter/1-Recommendations. Accessed December 10, 2017.

7. Ward MC, Shah C, Adelstein DJ, et al. Cost-effectiveness of nivolumab for recurrent or metastatic head and neck cancer. Oral Oncol. 2017;74:49-55. doi:10.1016/j.oraloncology.2017.09.017

8. Tringale KR, Carroll KT, Zakeri K, Sacco AG, Barnachea L, Murphy JD. Cost-effectiveness Analysis of Nivolumab for Treatment of Platinum-Resistant Recurrent or Metastatic Squamous Cell Carcinoma of the Head and Neck. J Natl Cancer Inst. 2018;110 (5):479-485. doi:10.1093/jnci/djx226.

9. Wissinger E, Griebsch I, Lungershausen J, Foster T, Pashos CL. The economic burden of head and neck cancer: a systematic literature review. PharmacoEconomics. 2014;32(9):865-882. doi:10.1007/ s40273-014-0169-3

10. Hashibe M, Brennan P, Chuang SC, et al. Interaction between tobacco and alcohol use and the risk of head and neck cancer: pooled analysis in the International head and neck cancer epidemiology consortium. Cancer Epidemiol Biomarkers Prev. 2009;18(2):541-550.

11. Jegu J, Binder-Foucard F, Borel C, Velten M. Trends over three decades of the risk of second primary cancer among patients with head and neck cancer. Oral Oncol. 2013;49(1):9-14. doi:10.1016/j. oraloncology.2012.06.018

12. Hollenbeak CS, Kulaylat AN, Mackley H, Koch W, Schaefer EW, Goldenberg D. Determinants of medicare costs for elderly patients with oral cavity and pharyngeal cancers. JAMA Otolaryngol Head Neck Surg. 2015;141(7):628-635. doi:10.1001/jamaoto.2015.0940

13. Gregoire V, Lefebvre JL, Licitra L, Felip E; Group E-E-EGW. Squamous cell carcinoma of the head and neck: EHNS-ESMOESTRO clinical practice guidelines for diagnosis, treatment and follow-up. Ann Oncol. 2010;21(Suppl 5):v184-186. doi:10.1093/ annonc/mdq185

14. Nijdam W, Levendag P, Noever I, Groot CU, Agthoven M. Cancer in the oropharynx: cost calculation of different treatment modalities for controlled primaries, relapses and grade III/IV complications. Radiat Oncol. 2005;77(1):65-72. doi:10.1016/j.radonc.2005.09.007

15. Agence Technique de l'Information sur l'Hospitalisation (ATIH). Aide À L'utilisation Des Informations De Chaînage [How to Use De-Identified Patient Information]. Lyon, France: Agence Technique de l'Information sur l'Hospitalisation; 2014.

16. Uhry Z, Belot A, Colonna M, et al. National cancer incidence is estimated using the incidence/mortality ratio in countries with local incidence data: is this estimation correct? Cancer Epidemiol. 2013;37 (3):270-277. doi:10.1016/j.canep.2012.12.007

17. Schulman KL, Berenson K, Tina Shih YC, et al. A checklist for ascertaining study cohorts in oncology health services research using secondary data: report of the ISPOR oncology good outcomes research practices working group. Value Health. 2013;16(4):655669. doi:10.1016/j.jval.2013.02.006

18. Amin MB, Edge S, Greene F, et al. AJCC Cancer Staging Manual. 8th ed. New-York: Springer-Verlag; 2017.

19. Barlow WE. Overview of methods to estimate the medical costs of cancer. Med Care. 2009;47(7 Suppl 1):S33-36. doi:10.1097/ MLR.0b013e3181a2d847

20. Charlson ME, Pompei P, Ales KL, MacKenzie CR. A new method of classifying prognostic comorbidity in longitudinal studies: development and validation. J Chronic Dis. 1987;40(5):373-383.
21. Boje CR. Impact of comorbidity on treatment outcome in head and neck squamous cell carcinoma - a systematic review. Radiat Oncol. 2014;110(1):81-90. doi:10.1016/j.radonc.2013.07.005

22. Quan H, Sundararajan V, Halfon P, et al. Coding algorithms for defining comorbidities in ICD-9-CM and ICD-10 administrative data. Med Care. 2005;43(11):1130-1139.

23. Bannay A, Chaignot C, Blotiere PO, et al. The best use of the Charlson comorbidity index with electronic health care database to predict mortality. Med Care. 2016;54(2):188-194. doi:10.1097/ MLR.0000000000000471

24. Institut National du Cancer (INCa). Algorithme De Sélection Des Hospitalisations Liées À La Prise En Charge Du Cancer Dans Les Bases Nationales D’activité Hospitalière De Court Séjour " Algorithme Cancer 》 [Algorithm to select cancer-related hospitalizations in the French National Hospital Discharge (PMSI) database]. Boulogne-Billancourt: INCa; 2013.

25. Distancier METRIC (MEsure des Trajets Inter-Communes/Carreaux)/ Calculs «Licencié », licence $n^{\circ} 201602996$ [computer program]; 2014.

26. Assurance Maladie. Rapport charges et produits pour l'année 2014. Assurance Maladie; July 11, 2013.

27. GBD. 2015 DALYs and HALE collaborators. Global, regional, and national disability-adjusted life-years (DALYs) for 315 diseases and injuries and healthy life expectancy (HALE), 1990-2015: a systematic analysis for the Global burden of disease study 2015. Lancet. 2016;388(10053):1603-1658. doi:10.1016/S0140-6736(16)31460-X

28. Buntin MB, Zaslavsky AM. Too much ado about two-part models and transformation? Comparing methods of modeling medicare expenditures. J Health Econ. 2004;23(3):525-542. doi:10.1016/j. jhealeco.2003.10.005

29. Manning WG, Mullahy J. Estimating log models: to transform or not to transform? J Health Econ. 2001;20(4):461-494.

30. GBD. 2015 Risk factors collaborators. Global, regional, and national comparative risk assessment of 79 behavioural, environmental and occupational, and metabolic risks or clusters of risks, 1990-2015: a systematic analysis for the Global burden of disease study 2015. Lancet. 2016;388(10053):1659-1724. doi:10.1016/S0140-6736(16) 31679-8

31. Simard EP, Torre LA, Jemal A. International trends in head and neck cancer incidence rates: differences by country, sex and anatomic site. Oral Oncol. 2014;50(5):387-403. doi:10.1016/j.oraloncology.2014.01.016

32. Zigon G, Berrino F, Gatta G, et al. Prognoses for head and neck cancers in Europe diagnosed in 1995-1999: a population-based study. Ann Oncol. 2011;22(1):165-174. doi:10.1093/annonc/mdq306

33. Guizard AV, Uhry Z, de Raucourt D, et al. Trends in net survival from head and neck cancer in six European Latin countries: results from the SUDCAN population-based study. Eur J Cancer Prev. 2017;26:S16-S23. doi:10.1097/CEJ.0000000000000296

34. St Guily JL, Borget I, Vainchtock A, Remy V, Takizawa C. Head and neck cancers in France: an analysis of the hospital medical information system (PMSI) database. Head Neck Oncol. 2010;2:22. doi:10.1186/1758-3284-2-22

35. Greenberg D, Earle C, Fang CH, Eldar-Lissai A, Neumann PJ. When is cancer care cost-effective? A systematic overview of cost-utility analyses in oncology. J Natl Cancer Inst. 2010;102(2):82-88. doi:10.1093/jnci/djp472

36. Neumann PJ, Cohen JT, Weinstein MC. Updating cost-effectivenessthe curious resilience of the \$50,000-per-QALY threshold. $N$ Engl J Med. 2014;371(9):796-797. doi:10.1056/NEJMp1405158 


\section{Publish your work in this journal}

ClinicoEconomics and Outcomes Research is an international, peerreviewed open-access journal focusing on Health Technology Assessment, Pharmacoeconomics and Outcomes Research in the areas of diagnosis, medical devices, and clinical, surgical and pharmacological intervention. The economic impact of health policy and health systems

organization also constitute important areas of coverage. The manuscript management system is completely online and includes a very quick and fair peer-review system, which is all easy to use. Visit http://www.dovepress.com/testimonials.php to read real quotes from published authors.

Submit your manuscript here: https://www.dovepress.com/clinicoeconomics-and-outcomes-research-journal 